University of Nebraska - Lincoln

DigitalCommons@University of Nebraska - Lincoln

Drought Mitigation Center Faculty Publications Drought -- National Drought Mitigation Center

2008

\title{
The Need for Integration of Drought Monitoring Tools for Proactive Food Security Management in Sub-Saharan Africa
}

\author{
Tsegaye Tadesse \\ University of Nebraska - Lincoln, ttadesse2@unl.edu \\ Menghestab Haile \\ United Nations World Food Programme (WFP) in Rome, Italy \\ Gabriel Senay \\ SAIC, U.S. Geological Survey (USGS), Earth Resources Observation and Science (EROS) Center, Sioux \\ Falls, South Dakota \\ Brian D. Wardlow \\ University of Nebraska - Lincoln, bwardlow2@unl.edu \\ Cody L. Knutson \\ University of Nebraska - Lincoln, cknutson1@unl.edu
}

Follow this and additional works at: https://digitalcommons.unl.edu/droughtfacpub

Part of the Climate Commons

Tadesse, Tsegaye; Haile, Menghestab; Senay, Gabriel; Wardlow, Brian D.; and Knutson, Cody L., "The Need for Integration of Drought Monitoring Tools for Proactive Food Security Management in Sub-Saharan Africa" (2008). Drought Mitigation Center Faculty Publications. 1.

https://digitalcommons.unl.edu/droughtfacpub/1

This Article is brought to you for free and open access by the Drought -- National Drought Mitigation Center at DigitalCommons@University of Nebraska - Lincoln. It has been accepted for inclusion in Drought Mitigation Center Faculty Publications by an authorized administrator of DigitalCommons@University of Nebraska - Lincoln. 


\title{
The need for integration of drought monitoring tools for proactive food security management in sub-Saharan Africa
}

\author{
Tsegaye Tadesse, Menghestab Haile, Gabriel Senay, Brian D. Wardlow and \\ Cody L. Knutson
}

\begin{abstract}
Reducing the impact of drought and famine remains a challenge in sub-Saharan Africa despite ongoing drought relief assistance in recent decades. This is because drought and famine are primarily addressed through a crisis management approach when a disaster occurs, rather than stressing preparedness and risk management. Moreover, drought planning and food security efforts have been hampered by a lack of integrated drought monitoring tools, inadequate early warning systems (EWS), and insufficient information flow within and between levels of government in many sub-Saharan countries. The integration of existing drought monitoring tools for sub-Saharan Africa is essential for improving food security systems to reduce the impacts of drought and famine on society in this region. A proactive approach emphasizing integration requires the collective use of multiple tools, which can be used to detect trends in food availability and provide early indicators at local, national, and regional scales on the likely occurrence of food crises. In addition, improving the ability to monitor and disseminate critical drought-related information using available modern technologies (e.g., satellites, computers, and modern communication techniques) may help trigger timely and appropriate preventive responses and, ultimately, contribute to food security and sustainable development in sub-Saharan Africa.
\end{abstract}

Keywords: Drought; Food security; Early warning system; Decision support system.

\section{Introduction}

Drought occurs in every part of the world and adversely affects the lives of millions of people each year, causing significant damage to economies, the environment, and property. It also affects each country differently, having a greater social impact on countries with poor economic conditions and fewer management options. The overall impact of a drought on a given country, and its ability to recover from the resulting human and material damage, depends on several vulnerability factors. For one set of people, severe drought may mean famine and loss of lives;

Dr. Tsegaye Tadesse is with the National Drought Mitigation Center (NDMC), University of Nebraska-Lincoln, Lincoln, Nebraska 68583, USA. E-mail: ttadesse2@unl.edu.

Dr. Menghestab Haile is with the United Nations World Food Programme (WFP) in Rome, Italy.

Dr. Gabriel Senay is with SAIC, U.S. Geological Survey (USGS), Earth Resources Observation and Science (EROS) Center, Sioux Falls, South Dakota 57198, USA.

Dr. Brian D. Wardlow and Dr. Cody L. Knutson are with the National Drought Mitigation Center, University of Nebraska-Lincoln, Lincoln, Nebraska 68583, USA. for another, the effects may be more monetary in nature. For example, in relatively wealthy countries with abundant agricultural resources and private social mechanisms, drought impacts may not be a direct matter of "life or death" as it is in countries where life depends on subsistence, rain-fed agriculture.

The occurrence of drought by itself does not necessarily cause food crises, but it can be a trigger for food insecurity. Economic, social, and political factors in many developing countries can considerably reduce the ability of households to access enough food to feed their families. This creates a situation of chronic food insecurity and vulnerability among the poorest households, which is accentuated during times of drought. Food emergencies not only threaten lives but also have a devastating long-term impact on the livelihoods of the households, as they are forced to divest their productive assets during an emergency. In many cases, long-term exposure to food insecurity has eroded households' ability to manage the adverse effects of drought, leading to situations of chronic crisis whereby households regularly face shortages in food and income. To cope with acute food shortages, households often diversify their food acquisition options and patterns, engaging in unsustainable livelihood 
strategies (Davies, 2000). In recent years, frequent droughts have occurred in many sub-Saharan countries, resulting in food crises for millions of people. In particular, recurrent droughts in Africa during the last 30 years have had a disastrous effect on an economic and social situation that already had serious problems (Haile, 2005; Tadesse, 1998). The traditional strategy among many countries in regard to natural disasters such as drought and food insecurity is crisis management and emergency relief. However, the enormous consequences of drought and the high financial cost of relief efforts have led some African decision makers to increase their efforts to implement more proactive drought preparedness and risk management strategies (UNDP, 2000).

Despite these advancements, additional work is needed to improve the integration of and access to accurate and timely monitoring and predictive tools to assist governmental and non-governmental decision makers in more effectively preparing for and responding to drought and food security issues (Tadesse et al., 2005). Technological advances (e.g., satellite observations, computing resources and communication technologies) coupled with better use of available drought monitoring tools also improve our ability to more effectively manage water and other shared natural resources during periods of drought.

The goal of this paper is to discuss and emphasize the need for improved integration of drought monitoring information available over sub-Saharan Africa to advance proactive drought and food insecurity risk management strategies within the region. There is a need for a paradigm shift from crisis to risk management, which is critical for improved food security. An effective, proactive risk management strategy requires that the best available information from operational and reliable drought monitoring tools for the region be collectively analyzed to provide objective information for near real-time food security assessments. All too often, food security decisions are based on the limited information from a single drought information product and the timely and consistent delivery of information can also be an issue. In many cases, the information may also be too broad-scale for local decision-making needs. Within this context, this paper has several general objectives:

1) Discuss food insecurity in sub-Saharan Africa and the historical patterns of drought frequency over the major farming systems that often lead to increased vulnerability in the region's food supplies (section 2).

2) Highlight institutional problems and barriers that impede the facilitation of the paradigm shift from crisis to risk management (section 3).

3) Discuss the need for management approaches that are based on the synthesis of climate and satellite information obtained from improved drought monitoring tools that are available for sub-Saharan Africa. This includes presenting several freely available, satellite-based monitoring products for Africa provided by an existing monitoring system, FEWS NET, and some of the limitations in the application of the products (section 4).

4) Present key points for building a more integrated early warning and food security information system in the African context, along with some general conclusions and recommendations for future work on this topic for sub-Saharan Africa (sections 5, 6, and 7).

\section{Background}

\subsection{Food insecurity in sub-Saharan Africa}

In sub-Saharan Africa, despite its vast reserves of natural resources and agricultural potential, millions of people currently suffer from chronic food insecurity and are exposed to recurrent food emergencies. According to the Food and Agriculture Organization (FAO, 2000), food insecurity is a situation that exists when people lack secure access to sufficient amounts of safe and nutritious food for normal growth and development and an active and healthy life. It may be caused by the unavailability of food, insufficient purchasing power, inappropriate distribution, or inadequate use of food at the household level. Food insecurity, poor conditions of health and sanitation, and inappropriate care and feeding practices are the major causes of poor nutritional status. Food insecurity may be chronic, seasonal, or transitory. Food insecurity is greater in sub-Saharan African countries than it is in other developing countries throughout the world (Haile, 2005; FAO, 2002). The main contributing factors to the vulnerability of these highly rural populations include high dependency on rain-fed agriculture, weak infrastructure, limited access to markets, limited employment opportunities, and increased disease burden from HIV AIDS and malaria (UN Millennium Project, 2005; Commission for Africa, 2005; UNDP, 2004). The above factors are compounded by commonly occurring natural hazards such as drought, which reduce rural populations' abilities to access food and sustain their livelihoods (Haile, 2005).

The problem of chronic hunger and malnutrition has taken centre stage as world leaders, national governments, the humanitarian community, and donor agencies have made commitments to address the root causes of hunger and reduce human suffering. This commitment was embodied in the Millennium Declaration of the United Nations Millennium Summit in September 2000. World leaders adopted the Millennium Development Goals (MDGs), which set clear targets for reducing poverty, hunger, disease, illiteracy, and discrimination against women by 2015 . Subsequently, the Johannesburg Declaration on Sustainable Development (September 2002) affirmed the MDGs and recognized that sustainable agriculture and rural development are essential for increasing food production and enhancing food security and safety in an environmentally sustainable manner (UN Millennium Project, 2005). 
However, despite these national and international efforts, many households in sub-Saharan Africa are still exposed to the risks of food shortages and hunger, and recurrent food crises and complex emergencies have constrained local and national economic development. The food crises of 1974, 1984-85, 1999, 2002, and more recently 2005 have resulted in acute hunger and malnutrition, loss of productive assets, and increased vulnerability to future risks (Haile, 2005). In dryland agriculture, a failure of the rainy season is directly linked to agricultural failure, which reduces food availability at the household level and rural employment possibilities (Dilley et al., 2005). Recovery from such drought events can take several years (Dercon, 2004). In addition, the poorest people in rural areas often occupy the most marginal lands, which are typically the most vulnerable to natural disasters (UNDP, 2004).

Food insecurity is particularly severe for populations in the most remote areas of sub-Saharan Africa. Access to markets and utilities is constrained by the lack of infrastructure and prohibitively high transport costs. Compared to other parts of the world, transport costs are highest in sub-Saharan Africa (Haile, 2005). In a typical sub-Saharan country, the cost of local transport can be as high as $\$ 800$ USD per metric ton, compared to $\$ 300$ USD in Asia (UN Millennium Project, 2005). Farmers cannot get their products to markets at a competitive price because of the high transport costs. Lack of appropriate storage facilities in remote areas also contributes to high post-harvest agricultural losses. Furthermore, agricultural inputs such as commercial fertilizers and seeds are often too expensive for farmers to afford. Household food security is also influenced by social vulnerability factors such as household health, composition, type of household head (e.g., male, female, or child), availability of employment, and social standing in the community and culture.

Natural hazards and economic shocks, if not addressed properly, can lead to increased environmental degradation, deforestation, and conflicts over resources, which could trigger political instability. Political instability can further exacerbate a country's vulnerability to natural hazards such as severe drought events. In response to recurrent food shortages, rural communities often expand cultivation into non-arable marginal areas that are unsuitable for cropping. This accelerates land degradation, soil erosion, and soil infertility, which in turn further reduces agricultural productivity and increases their vulnerability for crop failure. In addition, increased rates of deforestation for agricultural land expansion, wood fuel supply, and other wood product generation further accelerates environmental degradation in sub-Saharan Africa. Intensified competition for land resources resulting from expanding cultivation into traditionally pastoral areas increases the potential for conflicts between pastoralists and sedentary agriculturalists, which adds to the complex web of factors that heighten people's vulnerability to disasters such as drought in this region.
Many developing countries lack the necessary emergency preparedness and response capacities and financial means to protect their people from disasters and economic shocks (Skees et al., 2004). The problem of food security could further deteriorate with the current global food commodity demands and higher fuel energy prices because most nations in sub-Saharan Africa are net importers of food and energy (FAO, 2005; Glantz, 1994).

\subsection{Drought impacts on food security in sub-Saharan Africa}

Throughout Africa's history, droughts have occurred with varying degrees of frequency and intensity. DeRose et al. (1998) demonstrated that food shortage is not inevitable in regions such as sub-Saharan Africa that experience major production shortfalls because of drought. In an evaluation of the causes of food shortages, politics and management were implicated as much as, or more than, weather. In Africa, droughts have complex relationships with food shortages that are exacerbated by each country's economic, technological, managerial, and political capacities. However, in subSaharan Africa, drought is recognized as one of the main catalysts of food insecurity and hunger (FAO, 2003) because of the large extent of marginal lands used for food production that often experience annual and seasonal rainfall variability resulting in failure of crop yields.

In the past few decades, most severe droughts in subSaharan Africa have directly and/or indirectly resulted in food crises. These include the droughts of 1972-1974 and 1984-1985, which caused widespread famine in the Sahel and the Horn of Africa, affecting 25 African countries. The 1992-1993 drought that affected southern Africa also resulted in severe food shortages. The Horn of Africa was again severely affected in 2000-2001 and in 2002-2003. For example, in Ethiopia, the drought of 2002-2003 affected more than 13 million people (DPPC, 2005). In 2008, UNICEF estimated that 3.4 million people would need food aid as crops continued to fail in the growing season (UNICEF, 2008).

Studies show that the geographical patterns of poverty and food insecurity in Africa are closely correlated with the amount of rainfall, the length of the growing season, and the vulnerability to drought for a specific area (Clover, 2003; Haile, 2005). There is significant geographic overlap between sub-Saharan Africa's areas of major farming systems (i.e., areas of agricultural production) shown in Figure 1a (Dixon et al., 2001) and the highest frequency of drought events (Figure 1b) across most of the region (Haile, 2005). For example, the cereal-root mixed farming system (e.g., maize, sorghum, millet, cassava, yams, and legumes) extends from Guinea through northern Côte d'Ivoire to Ghana, Togo, Benin and the mid-belt states of Nigeria to northern Cameroon and some areas of central and southern Africa (Figure 1a). This farming system accounts for 246 million ha $(10 \%)$ of sub-Saharan Africa's total land area and 32 million 
(a)

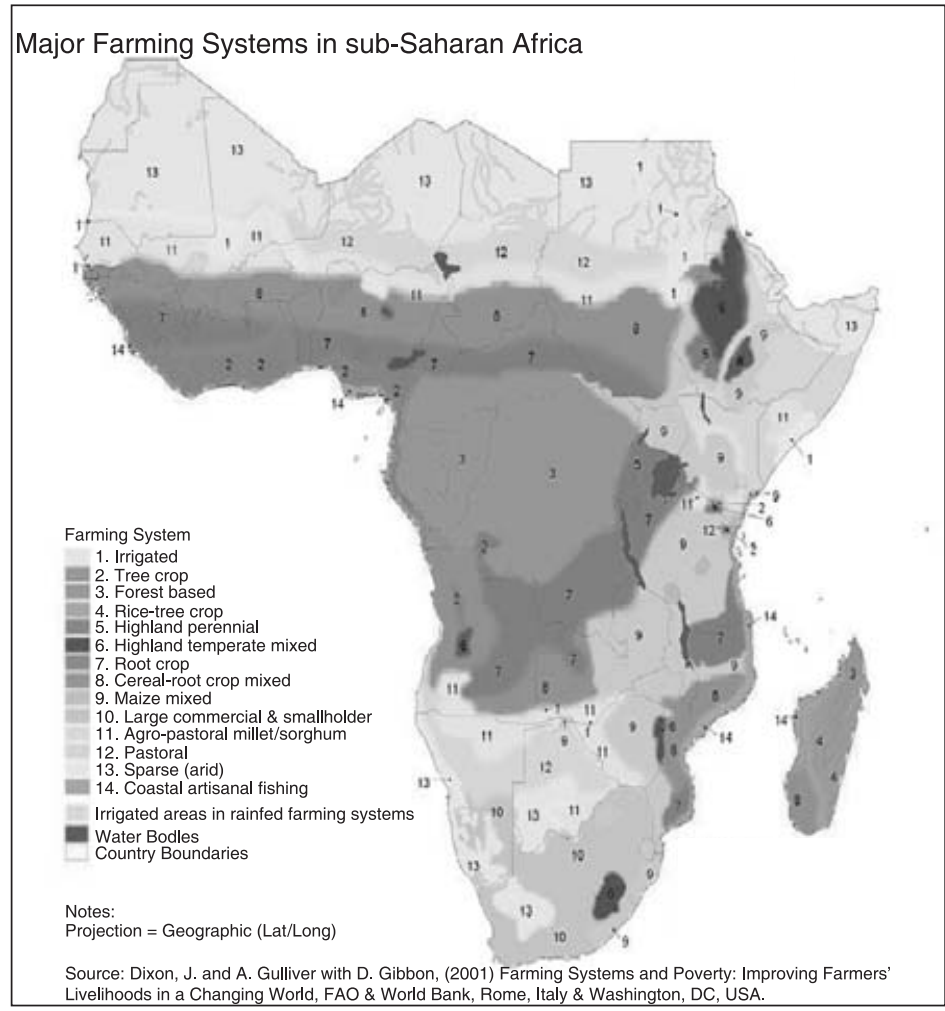

(b)

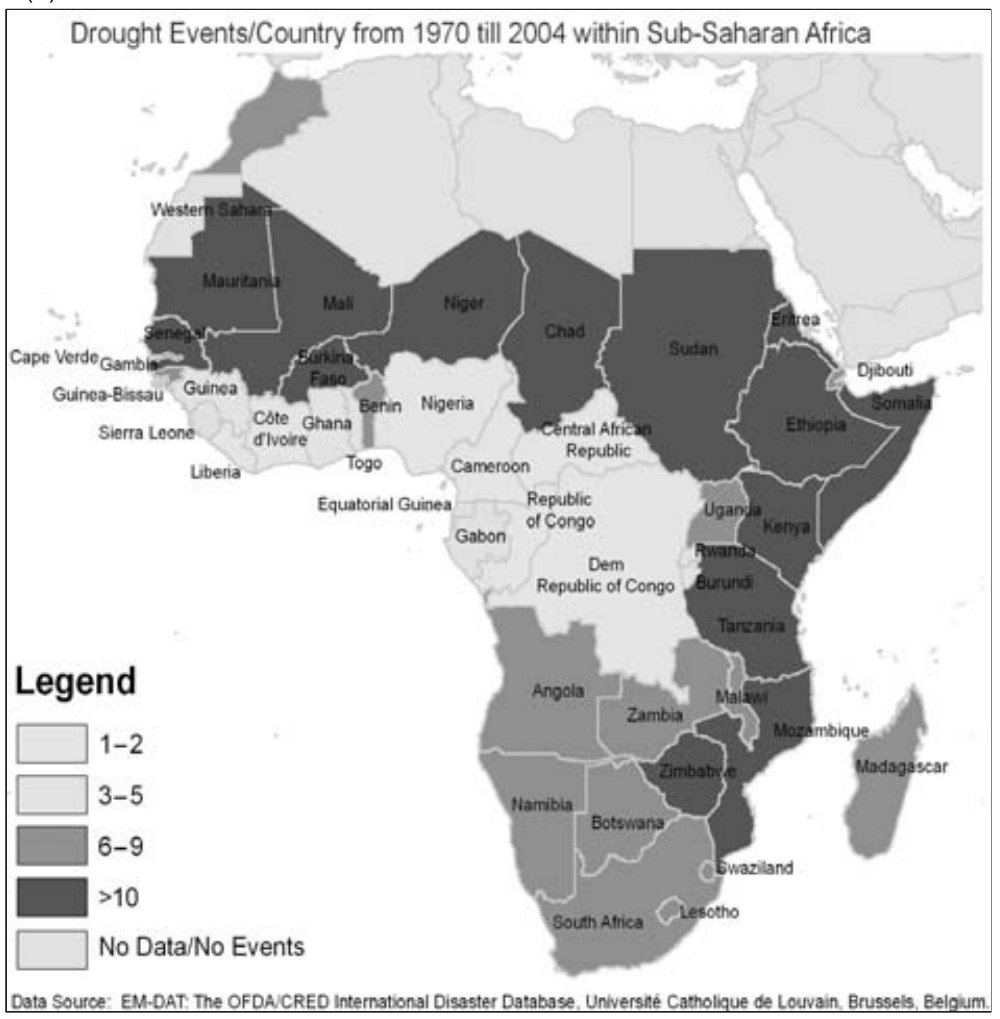

Figure 1. (a) Major farming systems in sub-Saharan Africa (after Dixon et al., 2001); (b) Number of drought reports per country in Africa from 1970 to 2004 (after Haile, 2005). 
ha $(19 \%)$ of the region's cultivated area, and it supports the livelihood of a primarily agrarian population of 60 million people (15\% of the region's total population). Dixon et al. (2001) suggest that this system could become the bread basket of Africa and an important source of export earning for the continent. However, frequent drought occurrences across this area (Figure 1b) result in both frequent and significant impacts on food security. Thus, the 200 million people estimated to reside in this region, which includes both pastoral and agro-pastoral production areas, are at risk of hunger and malnutrition (Haile, 2005). Figure 1a also shows that the eastern and southern African regions that extend from Ethiopia and Kenya to Tanzania, Zambia, Malawi, Zimbabwe, South Africa, Swaziland, and Lesotho have a maize mixed farming system (e.g., maize, tobacco, cotton, cattle, goats, and poultry), which is also a very important food production system for sub-Saharan Africa (Dixon et al., 2001). This farming system and the cereal-root crop mixed farming system discussed earlier are equally vulnerable to recurrent drought events as shown in Figure 1b.

The vulnerability of major farming systems to drought in sub-Saharan Africa highlights the notion that any agricultural development plan needs to consider the issues of climate, as most of the rural poor are dependent on traditional rainfed agriculture. In addition, proactive planning strategies must recognize that drought at varying levels of severity is a recurrent, naturally occurring event that has to be accounted for in any strategies that might be developed. Crop and pasture failure due to drought could be better predicted and communicated with improved monitoring and analysis of the factors that determine the local climate and its variability and the development of early warning systems (EWS) for enhanced information dissemination.

\section{Institutional problems and barriers that impede the facilitation of the paradigm shift from crisis to risk management}

\subsection{Institutional problems that limit the effectiveness of food security information and early warning systems}

In many African countries, institutional problems and barriers that limit the effectiveness of national food security information and EWS are often encountered, including:

1. A lack of food security policies, strategies, and political commitments. For many donors, international organizations, and decision makers, food security may not be a priority and governments may lack clear policies and regulations on food security and humanitarian interventions.

2. Poor integration of information into government structures. Typically, data collection and reporting functions are conducted separately by different ministries in the government, which often leads to data collection activities and policy-making processes being done independently with little or no information flow between the activities. People who collect and report food security data typically have no authority to make independent decisions and decision makers often do not have the full set of information from the field to make well-informed decisions.

3. Problematic relationships between donors and governments. Donors provide technical support and funding for national food security information systems, but governments may have their own priorities that do not align with those of the donor organization.

4. A lack of coordination between existing local and international food security information systems. This lack of coordination often leads to ineffective allocation of resources to the people who need help the most.

5. A lack of institutional memory. Systems are rarely institutionalized because of high staff turnover rates in the government and among donors and non-governmental organizations (NGOs), and this problem is compounded by short-term crisis management approaches to early warning.

6. A focus on emergency response rather than long-term planning. Political enthusiasm and donor support for EWS tends to be high in the aftermath of a famine but usually steadily declines over time.

Given these issues and constraints, the enhancement and improvement of food security and vulnerability monitoring systems in a given country or region is challenging (Glantz, 1996; Glantz, 1994). Addressing these difficulties is essential to enable a continuous assessment of the food security and livelihood status of communities and households, and to generate timely information that will allow governments and humanitarian agencies to plan and implement appropriate intervention options in addressing various stages of food insecurity. This may allow food security needs to be monitored at various aggregation units such as household, local, national, and regional levels. Monitoring should be undertaken through the careful selection of the most appropriate food security indicators that are associated with food availability, access, and utilization, which can be used for effective food security trend analysis.

\subsection{Challenges in establishing an effective drought monitoring system}

A stable, efficient drought monitoring system is required to facilitate a paradigm shift from crisis to risk management. At the national level, each individual country faces its own unique set of challenges for developing an improved drought monitoring system based on its specific natural, social, economic, and political resources. As a result, each nation may have to develop their drought monitoring systems differently according to their overall objectives and the information and technical resources that are available to them. However, for the development of an effective monitoring system, all countries and organizations must take the 
same initial first step, which is a thorough investigation of all available information resources and tools that are available at the national, regional, and continental scales that can be integrated into such a system. Many countries in subSaharan Africa have their own national meteorological services that provide climate information and predictions. However, the collection of agricultural and hydrological data is typically fragmented among many agencies and ministries because of the government structure of most of the countries (WMO, 2006). The World Meteorological Organization (2006) highlighted many challenges that are commonly faced in establishing drought monitoring and early warning systems including:

1. Meteorological and hydrological data networks are often inadequate in terms of the station density for collecting all major climate and water supply parameters required for these systems. Data quality is also a problem because of missing data and/or an inadequate length of record;

2. Data sharing is often inadequate between government agencies and research institutions, and the high cost of data also limits their application;

3. Information delivered through early warning systems is often too technical and detailed for decision makers to effectively use;

4. Forecasts are often unreliable on the seasonal timescale and lack the specificity required for use in agriculture and other sectors;

5. Climatic drought indices (e.g., Standardized Precipitation Index) are sometimes limited in their ability to detect the early onset and end of drought;

6. Comprehensive systems should be established that couple multiple climate, water, and soil parameters and socioeconomic indicators that fully characterize a drought's magnitude, spatial extent, and potential impact. These types of data are often lacking or incomplete for many countries;

7. Impact assessment methodologies, which are a critical part of drought monitoring and early warning systems, are not standardized or widely available, hindering impact estimates and the creation of regionally appropriate mitigation and response programs;

8. Delivery systems for disseminating drought information and data to users in a timely manner are often not well developed, limiting their usefulness for decision support. In addition, the quality, collection, and dissemination of meteorological data are key factors for their reliability and use of the drought monitoring products.

Although this list may not be comprehensive in terms of all the issues that may be faced within sub-Saharan Africa, it indicates the main challenges that most countries are likely to encounter. Each country will inevitably have other local and national problems and barriers that need to be considered in building a national drought monitoring system.

\section{Improving drought monitoring systems in Africa: paradigm shift from crisis to risk management}

Recurrent droughts and their significant effects on societies are increasingly forcing governments to play a more significant role in drought management in many parts of the world (UNISDR, 2007). The traditional mindset of governments in many countries, including Africa, has been to react to drought with a crisis management approach through the provision of relief or emergency assistance to the affected areas or sectors. With this approach, drought only receives the attention of decision makers when it is at the peak level of intensity and maximum spatial extent, which usually coincides with a time when management options are quite limited. This approach often results in measures that are ineffective, poorly coordinated, and untimely (Wilhite, 2000; Wilhite and Wood, 1994). This type of relief also often serves as a disincentive for the sustainable management of natural resources because it reinforces existing management practices that may not be sustainable in the long term.

Although emergency relief is often an important part of disaster management, nations are increasingly pursuing a more proactive approach that emphasizes the principle of risk management and sustainable development (Wilhite, 2000). In terms of drought, the risk management paradigm stresses the development of monitoring and EWS, the assessment of drought risk, and the implementation of drought mitigation and preparedness activities before the occurrence of drought. The goal of these activities is to reduce drought vulnerability and create societies that are more resilient and prepared for future drought events.

\subsection{Technological progress in improving drought monitoring and early warning systems}

Over the past 30 years, significant advances have been observed in drought monitoring. Since the occurrences of severe droughts in the 1980 s, national and international agencies have sought to improve their ability to predict food insecurity in sub-Saharan Africa and have implemented a number of early warning systems to monitor drought that may indicate the likelihood and magnitude of food insecurity (Speranza et al., 2008; Hutchinson, 1991). Drought has been monitored in sub-Saharan Africa using climatological data through the application of various statistical techniques (Hastenrath et al., 2007; Wang and Eltahir, 2000; Verschuren et al., 2000; Snijders, 1991). Remote sensing observations have also increasingly been used to assess the vegetation conditions and estimate rainfall at the national and regional drought monitoring centres (Chamaille-Jammes et al., 2006; Nicholson, 2005; Olsson et al., 2005).

At present, our ability to monitor and disseminate critical drought-related information has been enhanced by new technologies such as automated weather stations, improved satellite observations, advanced computing technology, and improved communication techniques (e.g., web delivery). 
This allows scientists and planners to further improve drought monitoring tools in sub-Saharan Africa at local, national, and regional scales. The tools could provide improved droughtrelated vegetation condition assessments and predictions to collectively analyze climate data from station networks that have increased spatial and temporal coverage and satellitebased earth observations that are now readily available at minimal cost. If such drought monitoring tools become part of a comprehensive EWS, they can provide decision makers with improved and timely information. Moreover, an EWS using improved drought monitoring tools can trigger timely and appropriate preventive measures if the country has adequate institutional capacity to communicate and implement recommendations or advisories. This allows decision makers to assess food security indicators to detect major changes in food availability and advise on the likely occurrence of food crises due to drought in advance of a severe event.

These efforts can facilitate the shift to risk management because they allow governments at the national, state, and local levels to address some of the more serious deficiencies of the crisis management approach. The following sections describe the use of current drought monitoring tools in subSaharan Africa within the context of early warning and food security systems. A discussion of some of the important actions that should be taken to enhance the integration of drought and food security systems is also presented.

\subsection{Using improved seasonal climate outlooks}

There has been a concerted regional and international effort to use climate information for practical applications in food security EWS. Currently, this is done in the form of Regional Climate Outlook Forums (RCOFs), where seasonal forecasts are prepared before each major growing season (WMO, 2008). The purpose of the Forums is to provide a consensus forecast for the region before each major rainy season and detail the possible implications for food security (Haile, 2005). In general, if appropriately developed, seasonal forecasts can help concerned stakeholders, such as agricultural planners, make proactive decisions on seasonal agricultural strategies (e.g., planting schedules, fertilizer distribution, and seed choice), future food and marketing needs, and further allocations of grazing areas for livestock. The seasonal outlooks can also be used by external agencies that assess food security and relief food requirements. In addition, information on possible droughts and disasters will help government officials, donors, and NGOs to prepare and allocate adequate resources to alleviate the potential problem.

\subsection{Agro-meteorological monitoring}

The livelihoods of most rural populations in sub-Saharan Africa are dependent on traditional agriculture that is dependent on seasonal rainfall. In this context, agrometeorological monitoring refers to the continuous assessment of rainfall and agricultural conditions. The start of a growing season (and hence agricultural activities) is determined by the arrival of adequate rains. Monitoring of the start of season (SOS) is critical and provides the first indication of the condition of the agricultural season. Once the rainy season has fully started, variations in the rainfall amount and distribution will determine the performance of crops, pasture, and other natural vegetation. The analysis of the timing of the start of the rainy season and the temporal and spatial variation through a region will highlight areas where the growing season is early, on time, or has a late onset. These are very important early indicators of the quality of the agricultural season and hence expected agricultural production.

Continuous monitoring of rainfall amount and distribution coupled with available crop growth models can be used for targeted areas, chosen on the basis of their agronomic importance and/or relevant meteorological events (e.g., areas with serious delay in the start of the rainy/growing season). The data used in this type of monitoring may include rainfall estimates over 10 days, number of rain days, vegetation index, and cumulative rainfall amounts (monthly or quarterly). Rainfall is often monitored using a combination of satellite rainfall estimates and ground measurements of rainfall from national networks (Funk et al., 2003; Hay and Lennon, 1999).

Various crop models have been developed for monitoring crop performance and estimating agricultural production for sub-Saharan Africa (Senay and Verdin, 2003). One of the most important variables in any crop model is rainfall, both in terms of its amount and distribution. Rainfall has different impacts on crops depending on the stage of the crop's development cycle (phenology) at the time the rainfall occurs. For the primary crops grown in an area, specific crop calendars have been developed that characterize the specific stages and timings of a crop's phenological events (e.g., sowing, emergence, flowering, maturation, and harvesting) during the growing season. Given that each crop has critical growth periods that determine the crop's production, crop calendar information can help target when assessment of a crop's vegetation condition is the most critical.

The capacity for large-area crop monitoring is rapidly improving because of improved satellite observations. Using satellite-based remote sensing technologies, scientists are now able to more accurately monitor cropped areas and estimate crop yields and production. The integration of crop model results such as the Water Requirement Satisfaction Index (WRSI) (Senay and Verdin, 2003), satellite-derived indicators of vegetation conditions such as the normalized difference vegetation index (NDVI), and field reports can often be used to identify widespread crop failures several weeks before the end of the growing season. The level of crop loss and expected crop production can be better estimated using an integration of these types of tools and information sources. For a given growing season, a Season Critical Period (SCP) can also be identified that indicates 
the critical months or weeks during the growing season that influence crop yields; datasets and information for this SCP can then be acquired to provide a more comprehensive assessment of expected crop yields.

Depending on the type of analysis and the information used, different decisions could be made. If the information indicates crop failure, further analysis would be initiated on the specific decisions that need to be made, which include humanitarian intervention and triggers for other response planning activities. On the other hand, if the analysis indicates an exceptional surplus harvest, then the decision would be to initiate a commodity marketing strategy to maximize profits. Several international and regional initiatives dealing with food security monitoring activities make use of climate information; these include USAID Famine Early Warning System (FEWSNET), FAO Global Information and Early Warning System (GIEWS), WFP Vulnerability Analysis and Mapping (VAM), Global Monitoring for Food Security (GMFS), Monitoring Agriculture with Remote Sensing (JRC-MARS FOOD), SADC Regional Early Warning System for Food Security (SADC-REWU), Regional Centre for Mapping Resources for Development (RCMRD), IGAD Climate Prediction and Analysis Center ICPAC, and Agro-meteorological and Hydro-meteorological (AGRHYMET).

For efficient food security monitoring, smooth and frequent information exchange among international, regional, and local institutions is essential. In addition, climate information and other improved drought monitoring products can provide better results if they are shared and implemented at local levels with a proper mechanism to collect feedback from local experts and users.

\subsection{Specific examples of agro-hydrological monitoring and early warning products that are freely available via FEWS NET}

Even though there are many challenges (e.g., institutional, technological, and financial difficulties) in building drought monitoring and EWS, there are some encouraging advances toward using new techniques to improve these applications in sub-Saharan Africa.

With the advent of grid-based remotely sensed rainfall data, the application of agro-hydrologic models for crop monitoring and yield forecasting has gained increased acceptance by various international, national, and local organizations. For example, FEWS NET at the US Geological Survey's (USGS) Center for Earth Resources Observation and Science (EROS) has been developing and distributing various agro-hydrologic digital products operationally at various temporal and spatial scales to monitor agricultural performance in parts of Africa for more than seven years. These satellite-derived products and water-balance model outputs from FEWS NET (Senay and Verdin, 2003) offer great potential in Africa for drought planning, preparation, and management and food security purposes. These new products, which are freely available via the internet, are highlighted in this paper to demonstrate how they can be used for drought and early warning systems.

The FEWS NET agro-hydrologic products include satellite-derived rainfall (Xie and Arkin, 1997), reference evapotranspiration (Senay et al., 2008), and the NDVI (Tucker et al., 2005) data. Typical satellite-derived products include onset-of-rains, soil moisture estimate, and crop performance indicators such as the crop WRSI (Verdin and Klaver, 2002; Senay and Verdin, 2003). In addition, summary charts showing temporal evolution of rainfall and NDVI are available by district and crop-growing zones for a large proportion of Africa.

The products are available on both a daily and dekadal (nominally 10-day) time step where each month is divided into three parts, with the 1 st and 2nd consisting of 10 days each and the last period varying between 8 and 11 days, depending on the month and year. The products provide supplementary independent information to that of the most commonly used NDVI. This information fits well with the principle of 'convergence of evidence' used in the EWS. For operational use, once the datastreams and model are setup, daily updates of soil water indicators can be generated easily and reliably. These operational products are available online at http://earlywarning.usgs.gov/adds/. These products, which include onset-of-rains, Soil Water Index (SWI), and crop WRSI maps, are briefly introduced and their potential uses within a drought monitoring system are discussed in the following sections.

\subsubsection{Onset-of-rains map}

Information on the onset of the growing season provides a tremendous advantage in planning and managing of agricultural activities. One seasonal product for Africa that is provided by FEWS NET is the onset-of-rains map. Figure 2 shows a sample map over the Sahel region of west Africa for the 3rd dekad of November 2007. Normally, the region's crop growing season runs from April to October, depending on the geographic location. For example, in Burkina Faso, the growing season is longer in the south, beginning in April, and shorter in the north, beginning in June. The onset-of-rains map is a surrogate for the SOS of the crop growing period. The SOS is defined with a simple rainfall accounting criteria: a total of $25 \mathrm{~mm}$ rainfall received in one dekad followed by a total of $20 \mathrm{~mm}$ in the following two consecutive dekads. The SOS map by itself provides critical information on potential crop performance of the season, especially if there is a significant delay in its establishment. In addition, the SOS map is used to initialize the crop water balance model, which simulates crop water use between the date of the SOS and the end of season (EOS) for each grid cell at $10 \mathrm{~km}$ resolution. The lengthof-growing season period (LGP) depends on the location and varies from a minimum of 7 dekads (70 days) in arid and semi-arid regions of the Sahel to 18 dekads (180 days) in mountainous and wetter regions of Africa. 


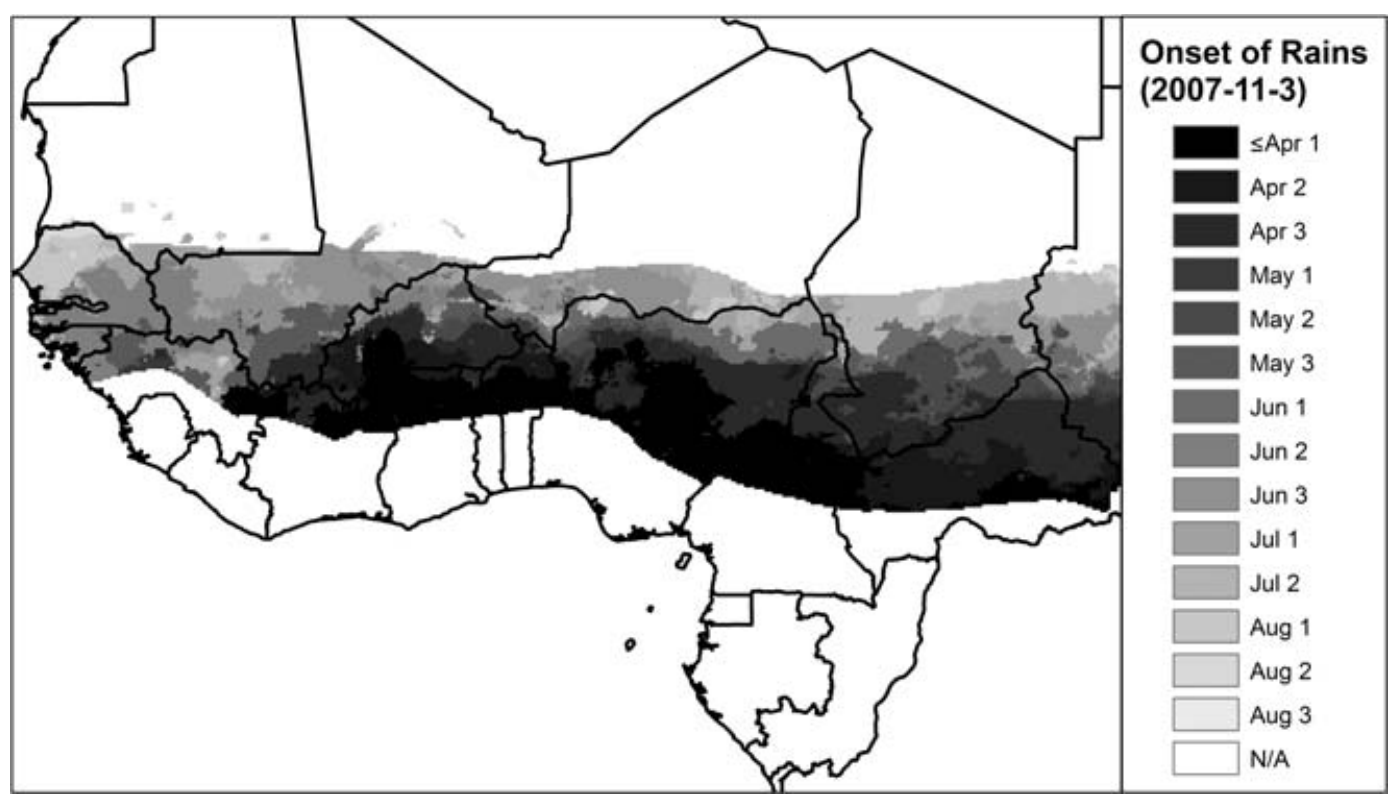

Figure 2. Start of season (dekads) for the 2007 growing season in the Sahel region of west Africa (e.g., Jun. 1 assumes farmers have planted their crops in the time period between Jun. 1 and Jun. 10, 2007).

\subsubsection{Soil Water Index (SWI)}

The availability of water in the root zone during the growing season is also important information for agricultural producers and decision makers. Figure 3 shows the soil water index (SWI) available online by FEWS NET for eastern Africa for the 1st dekad of July 2007. The SWI shows the level of soil water in the root zone as defined by the soil water holding capacity of the top $1 \mathrm{~m}$ of soil and represented as a percentage of the water holding capacity. The SWI image shows four broad classes for qualitative interpretations, including areas with less than or equal to $10 \%$ that are labeled as wilting. This is generally a trigger level for drought early warning. The image is interpreted along with a weekly forecast rainfall for this purpose. If the 7-day forecast rainfall is not promising, the areas with the lowest SWI category are expected to go into the crop wilting phase. This is considered critical and the location becomes a potential candidate for highlighting as impacted by drought if the data are corroborated by field information. For example, a large area of eastern Kenya, isolated areas in the Darfur region of the Sudan, and much of Somalia in Figure 3 fall into the "wilting" zone by the 1st dekad of July 2007. This is generally due to a dry spell (Darfur) or seasonally dry condition (Kenya/Somalia) during the preceding couple of weeks. Areas labeled as "no start" are locations where the SOS was not established because not enough rainfall was received to meet the SOS criteria. Areas classified as "yet to start" indicate that the normal onset of the rains is after the current dekad represented in Figure 3.

\subsubsection{Crop Water Requirement Satisfaction Index (WRSI)}

In planning and agricultural managing practices, the crop WRSI assists in making decisions. Figure 4 (a) shows the spatial distribution of maize crop WRSI for southern Africa as of the 2nd dekad of March 2007. The extended WRSI is a forecast estimate of WRSI at the end of the growing season. The extended WRSI is based on the balance of crop water demand and supply from the SOS until the EOS. The WRSI values are expressed as an index from 0 to 100 . Generally, areas receiving less than $50 \%$ of the water demand are considered to have failed while areas with values greater than $94 \%$ are considered to have received adequate rainfall for yield and biomass production. In the $94 \%+$ category, crop yield is more likely to be limited by other management factors (such as fertilizer use, seed variety, etc.) than by water.

Regions showing WRSI values between 50 and 95 are at different stages of yield reduction because of water shortage. The exact yield reduction is determined by the prevailing management practices in the region. Thus, using historical data from an administrative district, it is possible to formulate a mathematical relationship between WRSI and yield, which would allow the possibility of using WRSI to forecast yield beginning at the middle of the crop growing season. Although the product assumes a predominant crop type in the region, the results are also indicative of other cereal crops growing in the same region and season.

A WRSI anomaly map is also produced to illustrate a recent situation as it relates to conditions for that same period across the historical record as shown in the example for the 2nd dekad of March 2007 over southern Africa in Figure 4 (b). The anomaly map is generated by calculating the extended WRSI (Figure 4 (a)) as a percentage of the median WRSI generated using the median rainfall distribution. This is another way of looking at the model output to cancel out any potential errors in the model assumptions such as the assumed length of the growing season. As shown 


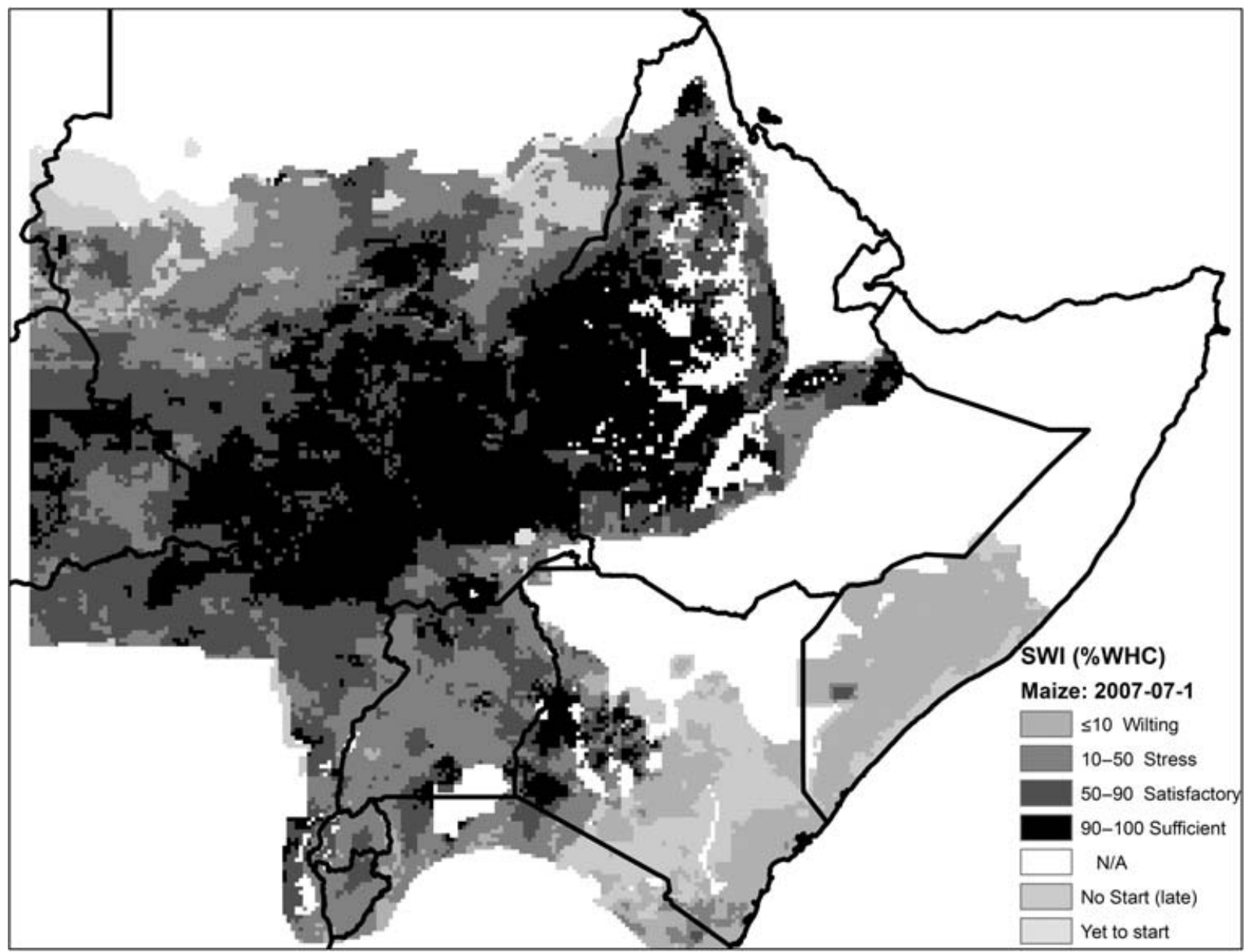

Figure 3. Soil Water Index as of the 1st dekad of July 2007. White areas indicate non-crop area masks.

in Figure 4 (b), much of southern Africa has performed about "average" (90-110\%) compared to the median WRSI. Large parts of southern Mozambique, Botswana, and southern Zimbabwe have performed below average (70-90\%) or much below average (50-70\%), and isolated regions such as north central Tanzania have performed above average $(>130 \%)$. This relative description was corroborated by field reports that showed widespread yield reductions in the above highlighted areas as well the improved crop performance in Tanzania.

\subsection{Limitations of current monitoring and Early Warning Systems in sub-Saharan Africa}

The above examples indicate that valuable information from satellite-based data and agro-hyrdrologic modeling is readily available and has great potential for monitoring, assessing, and providing early warning information related to drought and food security across Africa. However, a framework that enables data flow, institutional collaboration, and operational integration with locally available data should be established for decision makers in Africa in order to enhance more timely and effective decision making.
Because these products are generated using spatially explicit datasets, the model outputs can be easily improved, if necessary, to provide the level of detail required by a decision maker at a district level. One of the limiting factors for the use of the products at the national and sub-national scale could be the availability of sufficient computing resources and level of knowledge required to display, analyze, and interpret the model outputs. With the ever-declining prices for computer hardware/software, the cost of setting up such a system has become more affordable, especially when compared to the costs involved with making less informed decisions related to drought and food security. Most of the products are based on fundamental physical principles that can be easily understood from the accompanying documentation. With additional training, similar to that provided by the FEWS NET, decision makers will be able to conduct further analyses and customize the products for display and integration with locally available datasets.

These products are mainly used in monitoring drought conditions and estimating crop production for specific countries or regions as part of the USAID's Famine Early Warning activities. Products are traditionally accessed by international partners such as FAO and WFP and national 

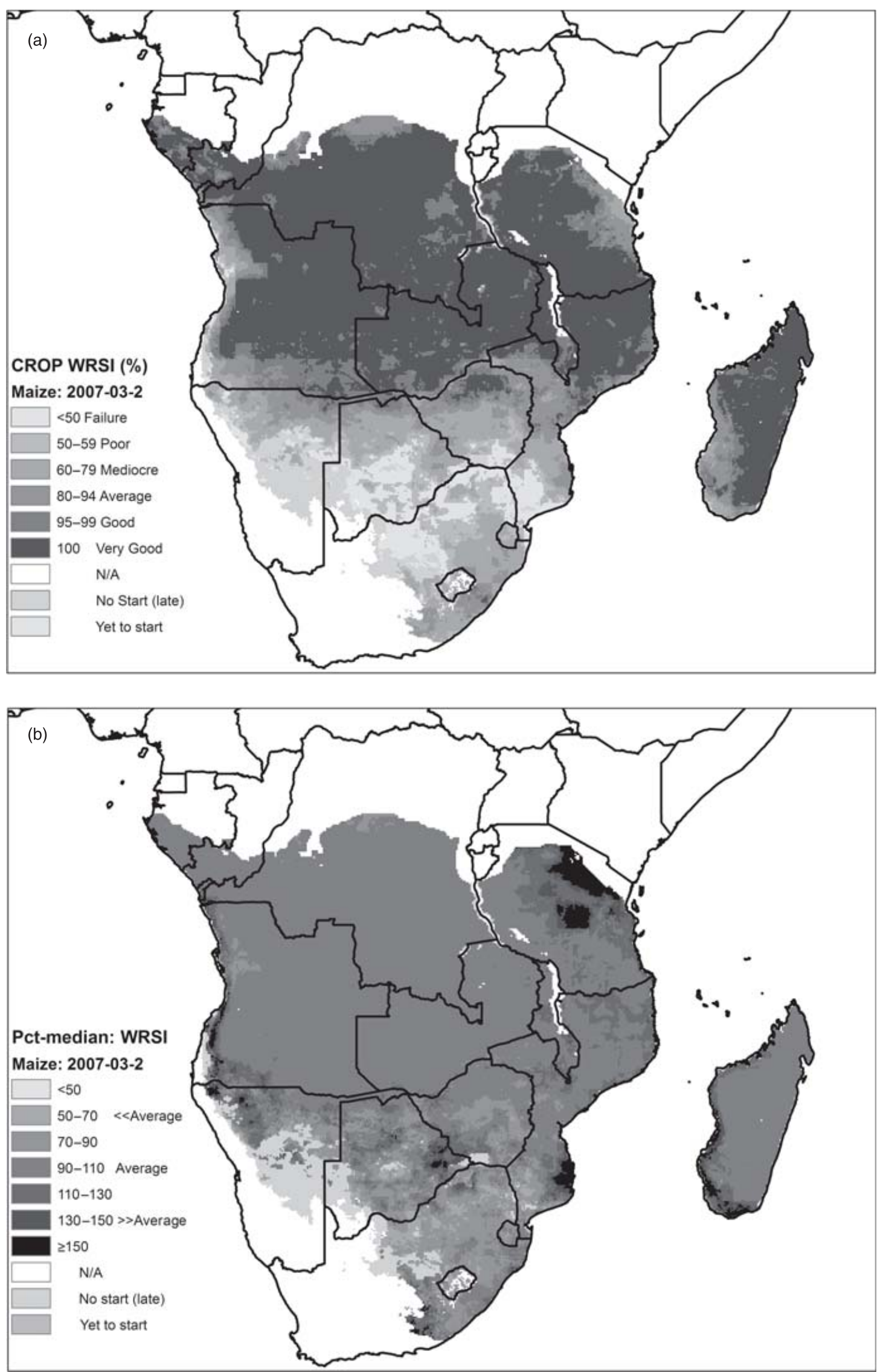

Figure 4. (a) Extended WRSI as of the second dekad of March 2007; (b) WRSI anomaly as of the 2nd dekad of March 2007. 
decision makers in the area of agriculture and water resources. The level of use of these products by national and subnational decision makers is unknown. Field reports by FEWS NET partners such as the US Department of Agriculture Foreign Agricultural Service (USDA FAS) confirm the reliability and usefulness of the various products in tracking overall agronomic field conditions at a district level (Reynolds, personal communication, 2005). Although a comprehensive study has not been conducted to document and assess the level of use by specific user communities, the FEWS NET monitoring and early warning products are widely distributed to USAID offices of Food for Peace (OFP) and Foreign Disaster Assistance (OFDA). In addition, international organizations such as the World Food Program (WFP) and FAO and nongovernmental organizations such as Save the Children and Care International also have access to these products. Similarly, FEWS NET's regional country representatives work with national institutions such as the ministry of agriculture and water resources to produce monthly country- and regional-scale reports. It is strongly recommended to establish a framework to facilitate the widespread use of these and similar products by decision makers at the district level throughout sub-Saharan Africa and the rest of the continent. Because of the global nature of the input data, models can be customized to monitor specific districts at a spatial resolution adequate to monitor, assess, and provide early warning for both agriculture and water resources.

\section{Building integrated early warning and food security information systems in the African context}

\subsection{Building a Decision Support System (DSS)}

Given the complexity of drought and the fact that its impacts can accumulate gradually over time and vary widely across many locations and sectors, a well-designed, integrated drought decision support system (DSS) is critical to developing and implementing effective food security planning strategies (Goddard et al., 2003). The specific components of such a DSS may vary from country to country, but the various systems should have the common goal of providing drought monitoring and early warning information that will assist in: 1) identifying geographical areas and communities that are threatened by acute food insecurity, 2) identifying main causes of food insecurity and risks to livelihoods, as well as indicators of the extent to which households and communities could be affected, 3 ) identifying various risk management efforts (i.e., coping strategies) that governments, communities, and households could undertake to deal with food shortages, and 4) providing opportunities for early detection of potential risks and initiation of strategies on how to address them and minimize their impacts. This paper focuses on proposing activities to strengthen the monitoring and early warning components of such a decision support system.

\subsection{Integrating early warning and food security monitoring}

The integration of drought early warning and food security monitoring systems is essential to reduce the impacts of drought, famine, and other related disasters in developing countries. Even though this integration could vary from country to country, it generally should include improved drought monitoring tools that trigger actions and identify drought-vulnerable areas and communities, as well as the main causes of food insecurity. These tools should also be used to determine the extent to which households could be affected and trigger contingency planning and emergency needs assessments, which regularly assess the nutritional status of people in the most severely affected areas and are used to support advocacy and resource mobilization efforts.

In order to provide appropriate assistance for drought mitigation, the first step would be to develop a better understanding of the spatial and temporal dimensions of who is at most risk. Extreme weather risk analysis can provide probabilities and scenarios of who would be the most affected, in what specific way they would be affected, and at what frequency. The type of analysis that is provided should integrate long-term rainfall data, agricultural statistics, market data, and socio-economic information.

Following the severe droughts of the past few decades, which caused major food crises in sub-Saharan Africa, many countries, with support from the international community, have initiated national and regional humanitarian response systems. For example, in Ethiopia, the Disaster Prevention and Preparedness Commission (DPPC), and in the Sudan, the Humanitarian Aid Commission (HAC), were established to address food emergencies (Haile, 2005). Similar government institutions exist in other countries. A drought emergency response framework may include various components such as food security monitoring systems to provide early warning information, strategic food reserve systems to enable timely delivery of food assistance, and contingency funds to enable the emergency operation.

To coordinate and harmonize their efforts, governments have also created regional groupings such as the Intergovernmental Authority on Development (IGAD), Southern African Development Community (SADC), and Permanent Interstate Committee for drought control in the Sahel (French: Comité permanent inter-État de lutte contre la sécheresse au Sahel, abbreviated as CILSS). One of the purposes of these regional institutions is to promote regional cooperation and facilitate sustainable development, as well as humanitarian intervention through improved regional food security information systems. In addition, regional centres providing climate services to member states have been created through international agreement. They include the 
African Centre for Meteorological Applications for Development (ACMAD) and AGRHYMET in Niamey, the SADC Drought Monitoring Centre in Harare, and the IGAD Climate Prediction and Applications Centre in Nairobi. Better communication and exchange of climate information between these and other local, regional and international institutions could provide better results in reducing the impacts of drought and food insecurity in sub-Saharan Africa.

\section{Future needs/recommendations}

A comprehensive and integrated approach is essential to more effectively monitor drought in sub-Saharan Africa and provide early warning to reduce the impact of this common natural hazard on food security. Studies have shown that there is often a lack of coordination between drought information being acquired and the food security systems in Africa (Haile, 2005; Clover, 2003). National meteorological services need to play a more prominent role not only in the provision of data, but also in the analysis and interpretation of the information in support of decision makers. The following recommendations could be used to move toward an integrated drought monitoring system for proactive food security strategies:

1. Enhanced data and product sharing between international and national agencies to support integrated drought and food security monitoring.

2. Enhanced integration of local data sets and their inclusion in national and international monitoring programs to enhance the accuracy and resolution of monitoring and early warning products.

a. Conduct local-scale research that focuses on the characteristics of drought and its probability of occurrence at national and sub-national levels. This should be undertaken based on the unique set of environmental challenges each country faces. Such studies should also address the improvement of the accuracy and usefulness of meteorological forecasts at these scales.

b. Avoid institutional rivalries and build cooperative working relations among various ministries and organizations. This is a key element for effective communication and information transfer. Improving coordination efforts among local and national institutions is critical for establishing an effective drought monitoring system and building proactive food security strategies.

c. Collaborate in capacity building of local and national institutions, as well as different ministries involved in drought monitoring and food security. This is extremely important for improving multi-dimensional approaches that address existing problems and barriers. Improved data and information sharing is critical to minimize redundant work and optimize the use of local resources.
3. Consider long- and short-term planning for problem solving, as well as the development and sustainability of long-term monitoring networks and systems. For example, the establishment of new stations in the areas with a sparse density of stations may be a long-term commitment, while the acquisition of readily available satellite-derived products is a shorter term activity to close any information gaps.

Identification and implementation of existing drought monitoring products that are freely available at the regional to continental scales via the internet can quickly provide information for better-informed decisions. Many international and regional institutions and organizations use one or more of these products. The applications and dissemination of information from these products can serve as a guide for those unfamiliar with these datasets. The accuracy assessment of these drought monitoring products at national and/or sub-national levels using local and indigenous knowledge is valuable to better understand their applicability for a specific location and to take full advantage of their information for operational monitoring purposes. The accuracy assessment results will also enhance the credibility and importance of these products with a wide range of decision makers.

\section{Conclusions}

Recurrent drought and famine in sub-Saharan Africa in the last few decades has had a disastrous effect on an economic and social situation that was already characterized by serious problems. With effective planning and mitigation strategies, the risks and associated impacts of such events can be reduced. However, the implementation of proactive measures will require a paradigm shift from crisis to risk management.

An effective, proactive risk management strategy requires that the best available information from operational and reliable drought monitoring tools must be collectively analyzed to provide objective information for near real-time food security assessments. Addressing institutional problems and barriers that limit the effectiveness of drought and famine monitoring and early warning systems is critical to enable decision makers, governments, and humanitarian agencies to plan and implement appropriate intervention measures to address various stages of food insecurity. Food security information derived from integrated early warning systems can be used for various intervention options such as triggering contingency planning and emergency needs assessments, support advocacy and resource mobilization efforts, and market intervention encouraging local purchase. It can also be used to support appropriate policy development for poverty and hunger issues, including the implementation of various government developmental priorities. 
Recent advances in developing new drought monitoring tools and crop forecasting techniques using seasonal forecasts are encouraging. These types of drought monitoring and early warning products that are freely available at national, regional, and continental scales via the internet may help many countries in sub-Saharan Africa that currently lack the necessary preparedness capacities and financial means to protect their people from natural disasters and economic downfalls.

\section{References}

Chamaille-Jammes, S., Fritz, H., Murindagomo, F., 2006. Spatial patterns of the rainfall-NDVI relationship at the seasonal and interannual timescales in an African savanna. International Journal of Remote Sensing, 27: 5185-5200.

Clover, J., 2003. Food security in sub-Saharan Africa. African Security Review, 12(1). Available online at http://www.iss.co.za/pubs/ASR/ 12No1/FClover.html.

Commission for Africa, 2005. Our Common Interest, Report of the Commission for Africa. London, UK. Available online at http:// 213.225.140.43/english/report/introduction.html.

Davies, S., 2000. Effective drought mitigation. In: Wilhite, D.A. (ed.), Drought: A Global Assessment, Routledge Press, New York, Chapter 28.

Dercon, S., 2004. Growth and shocks: Evidence from rural Ethiopia. Journal of Development Economics, 74: 309-329.

DeRose, L., Messer, E., and Millman, S., 1998. Who's Hungry? And How Do We Know? Food Shortage, Poverty, and Deprivation. United Nations University Press. Available online at http://www.unu.edu/ unupress/unupbooks/uu22we/uu22we00.htm\#Contents.

Dilley, M., Chen, R.S., Deichmann, U., Lerner-Lam, A.L., and Arnold, M., 2005. Natural disaster hotspots: A global risk analysis. Disaster Risk Management Series No.5, Washington, D.C.: World Bank.

Disaster Prevention and Preparedness Commission (DPPC), 2005. Ethiopia: National information on disaster reduction report. Proceedings of the World Conference on Disaster Reduction, Kobe-Hyogo, Japan, 18-22 January 2005. Available online at http://www.unisdr.org/eng/mdgsdrr/national-reports/Ethiopia-report.pdf.

Dixon, J., Gulliver, A., and D. Gibbon, 2001. Farming systems and poverty: Improving farmers livelihoods in a changing world. Rome, Italy, and Washington, DC: FAO and The World Bank. Available online at ftp://ftp.fao.org/docrep/fao/004/ac349e/ac349e00.pdf

Food and Agriculture Organization (FAO) of the United Nations, 2005. The state of food and agriculture. Food and Agriculture Organization, Rome, Italy. Available online at ftp://ftp.fao.org/docrep/fao/008/ a0050e/a0050e_full.pdf

Food and Agriculture Organization (FAO) of the United Nations, 2003. The state of food insecurity in the world: Monitoring progress towards the World Food Summit and Millennium Development Goals. Food and Agriculture Organization, Rome, Italy.

Food and Agriculture Organization (FAO) of the United Nations, 2002. The State of Food Insecurity in the World 2001. Food and Agriculture Organization, Rome, Italy.

Food and Agriculture Organization (FAO) of the United Nations, 2000. Handbook for Defining and Setting up a Food Security Information and Early Warning System (FSIEWS). Food and Agriculture Organization, Rome, Italy. Available online at http://www.fao.org/DOCREP/003/ X8622E/X8622E00.HTM

Funk, C., Michaelsen, J., Verdin, J., Artan, G., Husak, G., Senay, G., Gadain, H., and Magadazire, T., 2003. The collaborative historical African rainfall model: Description and evaluation. International Journal of Climatology, 23(1): 47-66.

Goddard, S., Harms, S.K., Reichenbach, S.E., Tadesse, T., and Waltman, W.J.,
2003. Geospatial decision support for drought risk management Communication of the ACM, 46(1): 35-37.

Glantz, M.H. (ed.), 1994. Usable science: Food security, early warning and El Niño. Proceedings of workshop, Budapest, Hungary, 25-28 October 1994. Environmental and Societal Impacts Group, National Center for Atmospheric Research, Boulder, Colorado, USA.

Glantz, M.H., 1996. Are famines so difficult to predict? Internet J. Afr. Stud. 1, April 1996.

Haile, M., 2005. Weather patterns, food security and humanitarian response in sub-Saharan Africa. Philosophical Transactions of the Royal Society B, 360(1463): 2169-2182.

Hastenrath, S., Polzin, D., and Mutai, C., 2007. Diagnosing the 2005 drought in Equatorial East Africa. Journal of Climate, 20(18): 4628.

Hay, S.I., and Lennon, J.J., 1999. Deriving meteorological variables across Africa for the study and control of vector-borne disease: Comparison of remote sensing and spatial interpolation of climate. Tropical Medicine and International Health, 4(1): 58-71.

Hutchinson, C.F., 1991. Uses of satellite data for famine early warning in sub-Saharan Africa. International Journal of Remote Sensing, 12(6): 1405-1421.

Nicholson, S., 2005. On the question of the "recovery" of the rains in the West African Sahel. Journal of Arid Environments, 63(3): 615-641.

Olsson, L., Eklundh, L., Ardö J., 2005. A recent greening of the Sahel trends, patterns and potential causes. Journal of Arid Environments, 63(3): 556-566.

Senay, G.B., and Verdin, J., 2003. Characterization of yield reduction in Ethiopia using a GIS-based crop water balance model. Canadian Journal of Remote Sensing, 29(6): 687-692.

Senay, G.B., Verdin, J.P., Lietzow, R., and Melesse, A.M., 2008. Global daily reference evapotranspiration modeling and evaluation. Journal of American Water Resources Association, 44(3): 1-11.

Skees, J.R., Varangis, P., Larson, D., and Siegel, P., 2004. Can financial markets be tapped to help poor people cope with weather risks? In: Dercon, S. (ed.), Insurance against Poverty, Oxford University Press, Oxford, UK, pp. 422-437.

Snijders, F.L., 1991. Rainfall monitoring based on Meteosat data - a comparison of techniques applied to the Western Sahel. International Journal of Remote Sensing, 12(6): 1331-1347.

Speranza, C.I., Kitemeb, B., and Wiesmanna, U., 2008. Droughts and famines: The underlying factors and the causal links among agropastoral households in semi-arid Makueni district, Kenya. Global Environmental Change, 18(1): 220-233.

Tadesse, T., Brown, J.F., and Hayes, M.J., 2005. A new approach for predicting drought-related vegetation stress: Integrating satellite, climate, and biophysical data over the U.S. central plains. ISPRS Journal of Photogrammetry and Remote Sensing, 59(4): 244-253.

Tadesse, T., 1998. Improving drought management and planning through better monitoring in Africa. Drought Network News, 10(2): 3-8.

Tucker, C.J., Pinzon, J.E., Brown, M.E., Slayback, D., Pak, E.W., Mahoney, R., Vermote, E., and El Saleous, N., 2005. An extended AVHRR 8-km NDVI data set compatible with MODIS and SPOT vegetation NDVI data. International Journal of Remote Sensing, (14): 4485-4498.

United Nations International Strategy for Disaster Reduction (UNISDR), 2007. Drought risk reduction framework and practices: Contributing to the implementation of the Hyogo Framework for Action. United Nations secretariat of the International Strategy for Disaster Reduction, Geneva, Switzerland.

UN Millennium Project, 2005. Investing in Development: A Practical Plan to Achieve the Millennium Development Goals (ed. J.D. Sachs). Earthscan Publications, London.

UNDP (United Nations Development Program), 2004. Reducing disaster risk: A challenge for development. UNDP Bureau for Crisis Prevention and Recovery, New York. Available at http://www.undp.org/cpr/ whats_new/rdr_english.pdf.

UNDP (United Nations Development Programme), 2000. Report on the Status of Drought Preparedness \& Mitigation in Sub-Saharan Africa. UNDP / Drylands Development Centre, Nairobi, Kenya. 
UNICEF (United Nations Children's Fund), 2008. UNICEF makes plea for additional resources to help stave off malnutrition in Ethiopia. Published on ReliefWeb at http://www.reliefweb.int/rw/rwb.nsf/ db900sid/KKAA-7F98AF?OpenDocument\&rc=1\&emid=ACOS-635NZE

Verdin, J., and Klaver, R., 2002. Grid cell based crop water accounting for the famine early warning system. Hydrological Processes, 16: 1617-1630.

Verschuren, D., Laird, K.R., and Cumming, B.F., 2000. Rainfall and drought in equatorial east Africa during the past 1,100 years. Nature, 403: 410-414.

Wang, G., and Eltahir, E.A.B., 2000. The Role of vegetation dynamics in enhancing the low-frequency variability of the Sahel rainfall, Water Resources Research, 36(4): 1013-1021.

Wilhite, D.A., 2000. Preparing for drought: A methodology, in Wilhite, D.A. (ed.) Drought: A Global Assessment, Routledge Press, New York.
Wilhite, D.A., and Wood, D.A., 1994. Drought management in a changing West: New directions for water policy. IDIC Technical Report 94-1. International Drought Information Center, University of NebraskaLincoln.

World Meteorological Organization (WMO), 2008. Regional Climate Outlook Forums (RCOFs). Available at http://www.wmo.ch/pages/ $\mathrm{prog} / \mathrm{wcp} / \mathrm{wcasp} /$ documents/RCOFsBrochure.pdf.

World Meteorological Organization (WMO), 2006. Drought monitoring and early warning: Concepts, progress and future challenges. WMO No. 1006. Available at http://www.wmo.ch/pages/publications/showcase/ documents/1006_E.pdf

Xie, P., and Arkin, P.A., 1997. A 17-year monthly analysis based on gauge observations, satellite estimates, and numerical model outputs. Bulletin of the American Meteorological Society, 78(11): 2539-2558. 